\title{
Establishing a Lot through Sanitation Clean Breaks in Produce Packing Facilities ${ }^{1}$
}

\author{
Matthew D. Krug, Benjamin Chapman, and Michelle D. Danyluk ${ }^{2}$
}

\section{Why have clean breaks?}

Many produce packers establish lots for traceability reasons and to limit risk to their business in the event of a foodsafety contamination event. Whether a packer determines a lot by date, grower, field, buyer, or some other means, a clean break is needed before and after the production of that lot for it to be considered separate from other production. As has been noted in a number of recent produce outbreaks and recalls, the lack of a defined clean break can expand a food safety event to cover an entire production season.

This document is intended to highlight the importance of sanitation clean breaks in produce packing facilities and identify what is needed for a clean break to be established.

\section{What is a sanitation clean break?}

A sanitation clean break, commonly referred to as simply a "clean break," is a defined production break that involves a documented, verified, and validated cleaning and sanitation process of food contact surfaces. Under the Food Safety Modernization Act (FSMA)'s Produce Safety Rule (PSR), food contact surfaces are defined as “...those surfaces that contact human food and those surfaces from which drainage, or other transfer, onto the food or onto surfaces that contact the food ordinarily occurs during the normal course of operations." These surfaces include the food contact surfaces of equipment and tools used during harvest, packing, and holding.

\section{What is the difference between cleaning and sanitizing?}

Cleaning is commonly defined as the removal of physical soil or debris from a surface. Soil in a packing facility may include: plant debris, earth, mud dust, rust or other mineral deposits, wax buildup, PLU stickers or adhesives, biofilms, etc.

Sanitizing is commonly defined as the reduction of microorganisms on a cleaned surface. Unless a surface is clean, it is extremely difficult to sanitize. Soil remaining on the surface may interact with the sanitizing chemical, either preventing close contact between the surface and the sanitizer or inactivating the sanitizing agent.

\section{Establishing a Clean Break}

The recommendations below are drawn from Good Agricultural Practices (GAPs), Best Management Practices (BMPs), Good Manufacturing Practices (GMPs), and the scientific literature.

All food contact surfaces (often described as Zone 1 in food processing and manufacturing) need to have a sanitary

1. This document is FSHN13-10, one of a series of the Food Science and Human Nutrition Department, UF/IFAS Extension. Original publication date August 2013. Revised June 2020. Visit the EDIS website at https://edis.ifas.ufl.edu.

2. Matthew D. Krug, state specialized agent, food science, UF/IFAS Southwest Florida Research and Education Center; Benjamin Chapman, assistant professor, Department of 4-H Youth Development and Family \& Consumer Sciences, North Carolina State University; and Michelle D. Danyluk, professor, Food Science and Human Nutrition Department, UF/IFAS Citrus REC; UF/IFAS Extension, Gainesville, FL 32611.

The Institute of Food and Agricultural Sciences (IFAS) is an Equal Opportunity Institution authorized to provide research, educational information and other services

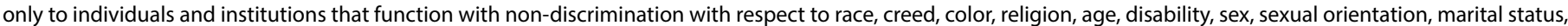

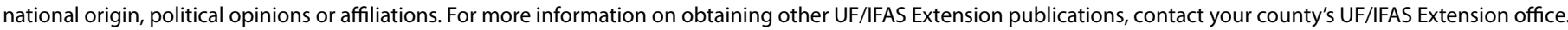
U.S. Department of Agriculture, UF/IFAS Extension Service, University of Florida, IFAS, Florida A \& M University Cooperative Extension Program, and Boards of County Commissioners Cooperating. Nick T. Place, dean for UF/IFAS Extension. 
design and be constructed in a way that they can be cleaned and sanitized.

Sanitation standard operating procedures (SSOPs) for cleaning and sanitizing need to be in place at a facility and specifically designed for that facility. These SSOPs should:

- Identify the exact surfaces or area to be cleaned and sanitized and defined by the packer as a food contact surface, and specify protocols by which different surfaces will be cleaned.

- Specify the frequency at which each procedure will be conducted, and identify the employee responsible for the procedure.

- Evaluate the condition of the food contact surfaces to ensure that they can be cleaned and sanitized.

- Identify compounds used and how they are used (may include: concentration, mixing procedure and water source; $\mathrm{pH}$, contact time, and temperature; and rinse procedure, if applicable).

All compounds used for the purpose of cleaning and sanitizing food contact surfaces should be labeled and validated as suitable for this use.

Records that support the SOPs must be completed and available. Records should include time/date of cleaning/ sanitation activity, a log of compound concentration, and the individual(s) who carried out the tasks.

Following any issues, Corrective Action records should be kept to indicate steps were taken to restore sanitary conditions, rework or divert any product that may have been processed under unsanitary conditions, and document actions taken to prevent this issue from occurring in the future.

A lot size should be determined by the packer based on when complete clean breaks are conducted (a clean break, as described above, would be required before and after a lot). A documented clean break between lots serves as a break in continuity between affected lots in the occurrence of a food safety event.

\section{Quick Facts about Clean Breaks}

- Food contact surfaces need to be cleanable and sanitizable.

- Procedures for cleaning and sanitation should be documented and include location, frequency, and chemicals used.

- Chemical compounds for cleaning and sanitation should be validated for their intended use and employed according to the manufacturer's directions.

- Documenting when, how, and why cleaning and sanitation occurred is necessary to establish a lot. 